\title{
Efficient production of trophoblast lineage cells from human induced pluripotent stem cells
}

\author{
Junya Kojima ${ }^{1,2}$, Atsushi Fukuda ${ }^{1}$, Hayato Taira' ${ }^{1}$, Tomoyuki Kawasaki ${ }^{1}$, Hiroe Ito², Naoaki Kuji², Keiichi Isaka², \\ Akihiro Umezawa ${ }^{1}$ and Hidenori Akutsu ${ }^{1,3}$
}

Human induced pluripotent stem cells (hiPSCs) are potentially useful in both clinical applications and basic biological research. hiPSCs can differentiate into extra-embryonic cells in the presence of BMP4. However, the differentiation potential of hiPSCs can be affected by culture conditions or genetic variation. In this study, we investigated the effect of various BMP4 concentrations on the expression states of trophoblast markers and the optimal conditions for trophoblast induction. A high-fidelity gene expression assay using hiPSC lines showed that the expression levels of various trophoblast marker genes, such as KRT7, GCM1, CGB, and HLA-G, were upregulated by BMP4 in a dose-dependent manner in all types of hiPSCs used in this study. Treatment with high doses of BMP4 for prolonged periods increased the ratio of cells with trophoblast markers irrespective of the presence of bFGF. We found that the expression states of major pluripotency- and differentiation-related protein-coding genes in BMP4-treated cells depended on culture conditions rather than donor cell types. However, miRNA expression states were affected by donor cell types rather than BMP4 dose. Furthermore, the effect of the presence of bFGF on differentiation potential of KRT7-positive cells differed among iPSC types. Mechanistically, chromatin states around KRT7 promoter regions were comparable among the iPSC types used in this study, indicating that hiPSC chromatin state at these regions is not a parameter for cytotrophoblast differentiation potential. In conclusion, the optimal conditions for trophoblast differentiation from hiPSCs differ according to parental cell line.

Laboratory Investigation (2017) 97, 1188-1200; doi:10.1038/labinvest.2016.159; published online 13 March 2017

Human embryonic stem cells and induced pluripotent stem cells are useful as research tools for resolving questions about basic biological phenomena and for cell transplantation and drug screening in regenerative medicine. ${ }^{1}$ Although most studies demonstrated that human pluripotent stem cells (hPSCs) can differentiate into embryonic tissue, ${ }^{2}$ they can also differentiate into extra-embryonic tissues. ${ }^{3}$ As it is difficult to study differentiating trophoblasts in vivo, hPSCs offer an attractive ex vivo model for human placentation. Moreover, the placenta is an essential organ for proper embryonic development and pregnancy maintenance in humans and its dysfunction is thought to be related with pregnancy-specific diseases, such as fetal growth restriction and pregnancy-induced hypertension. ${ }^{4,5}$ Therefore, the determination of optimal conditions for trophoblast differentiation from hiPSCs is useful for understanding pregnancyassociated diseases.
The most common method for derivation of trophoblasts from hPSCs involves exposing a culture of pluripotent stem cells to bone morphogenetic protein 4 (BMP4) in the absence of basic fibroblast growth factor (bFGF) ${ }^{6,7}$ BMP4 is a key protein of the TGF- $\beta$ super family that is essential for various cellular activities. ${ }^{8}$ In myeloma cell lines, BMP4 inhibits DNA synthesis in a dose-dependent manner. ${ }^{9}$ An initial study of the generation of trophoblast cells from human embryonic stem cells revealed dose-dependent morphological changes of BMP $4 .{ }^{3}$ However, a study reported that BMP4-treated hPSCs are not able to differentiate into trophoblast cells, instead differentiating into mesoderm. ${ }^{10}$ Different differentiation protocols are often used in different studies, and varying culture conditions may have resulted in conflicting observations. ${ }^{11,12}$ Furthermore, given that the genetic background of human induced pluripotent stem cells (hiPSCs) is predominantly responsible for transcriptional and epigenetic

\footnotetext{
${ }^{1}$ Center for Regenerative Medicine, National Research Institute for Child Health and Development, Tokyo, Japan; ${ }^{2}$ Department of Obstetrics and Gynecology, Tokyo Medical University, Tokyo, Japan and ${ }^{3}$ Department of Stem Cell Research, Fukushima Medical University, Fukushima City, Fukushima, Japan

Correspondence: Dr H Akutsu, MD, PhD, Center for Regenerative Medicine, National Research Institute for Child Health and Development, 2-10-1 Okura, Setagaya, Tokyo 157-8535, Japan.

E-mail: akutsu-h@ncchd.go.jp

Received 12 November 2016; revised 14 December 2016; accepted 19 December 2016
} 
a
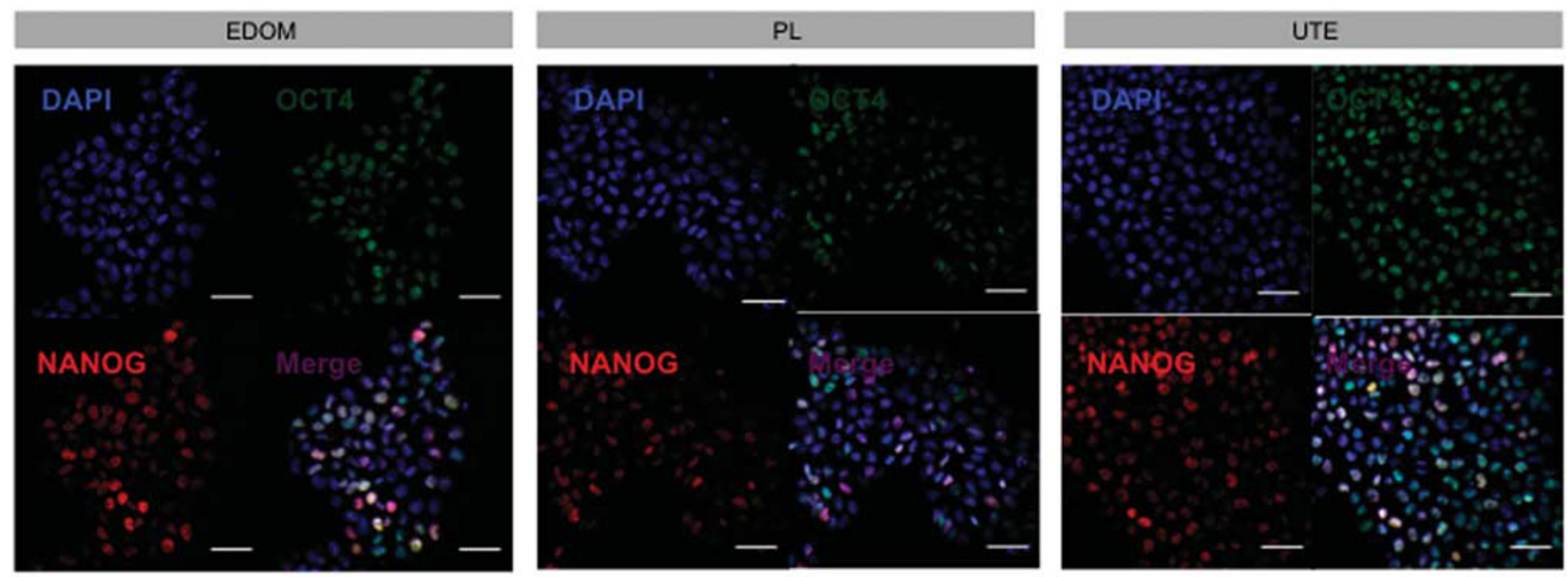

b
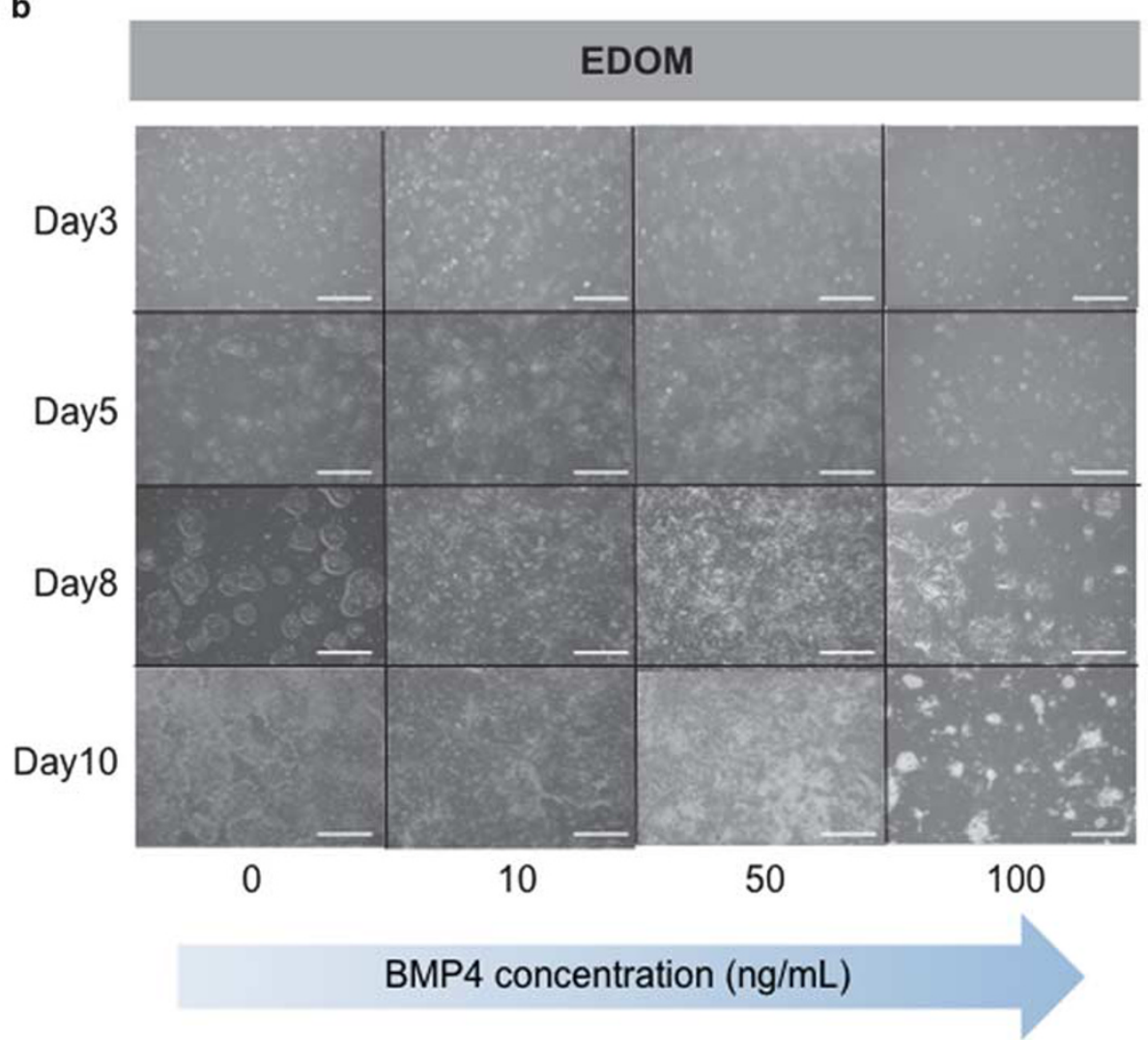

Figure 1 Effect of BMP4 concentration on cellular viability. (a) Expression of NANOG and OCT4 in hiPSC lines. Blue (DAPI), red (NANOG), and green (OCT4). Scale bar $=50 \mu \mathrm{m}$. (b) Morphology of cells treated with various concentrations of BMP4. Scale bar $=500 \mu \mathrm{m}$. (c) Population doublings (PDs) of BMP4-treated cells. The average PDs of three independent experiments are shown. Error bars are s.e. (d) Apoptosis assay of cells treated with 10 and $100 \mathrm{ng} / \mathrm{ml} \mathrm{BMP4}$ for 10 days. Values shown are averages of three independent experiments.

differences, ${ }^{13}$ there may be different optimal conditions for trophoblast differentiation of hiPSCs.

In this study, in order to define molecular features of BMP4-mediated differentiated cells and optimal conditions for efficient production of trophoblast cells, we conducted a large-scale, high-fidelity gene expression assay following treatment of differentiated cells with various concentrations of BMP4. The results indicated that BMP4 treatment robustly induced trophoblast differentiation. The expression levels of protein-coding genes associated with pluripotency and differentiation in BMP4-treated cells were dependent on culture conditions, while those of miRNAs were affected by 

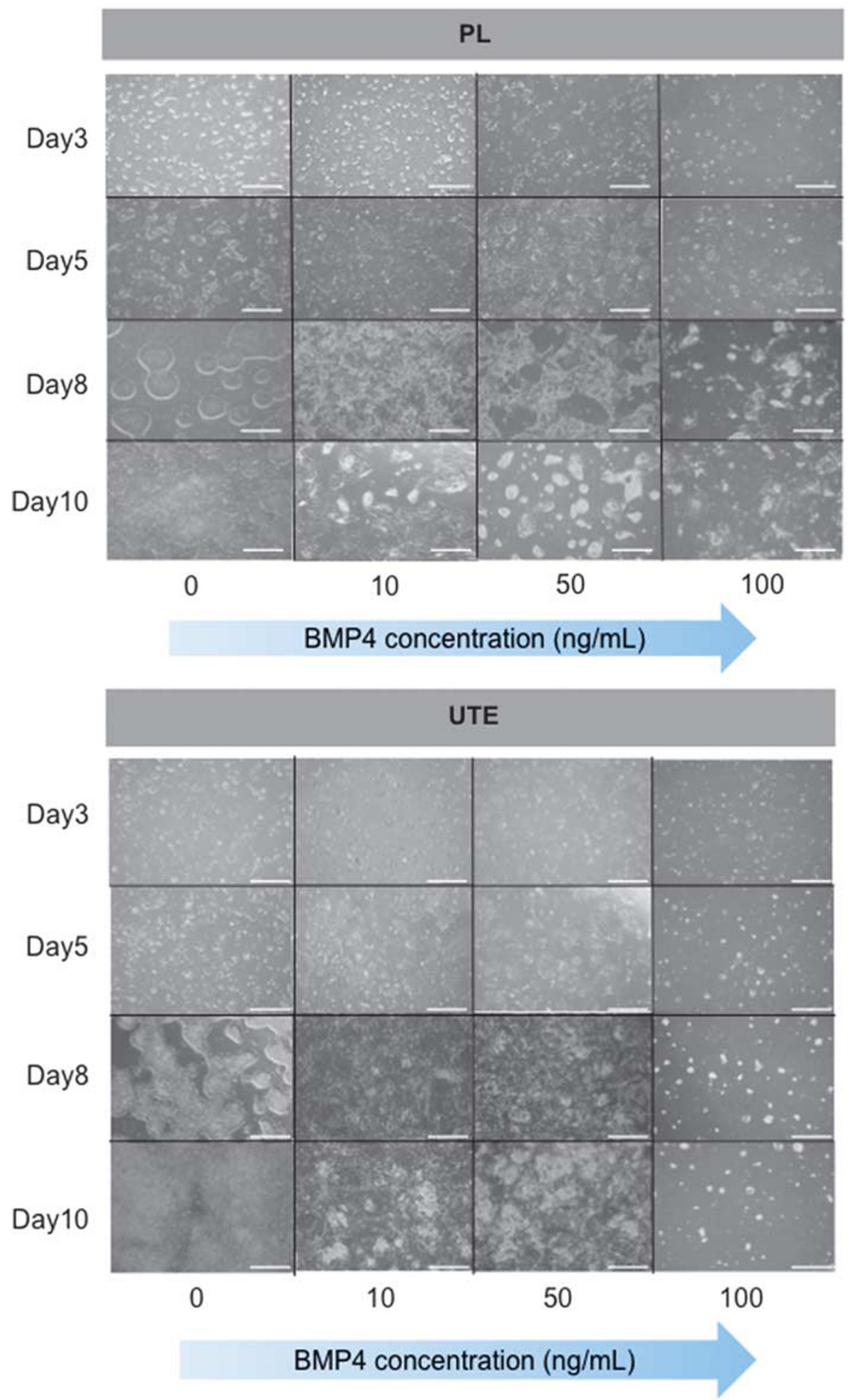

Figure 1 Continued.

cell type. We also found that the presence or absence of bFGF had an impact on trophoblast differentiation. Thus our findings demonstrate that there are optimal conditions for BMP4-induced trophoblast differentiation from hiPSCs.

\section{MATERIALS AND METHODS Ethics Statement}

Human placental cells were collected from surgical specimens with signed informed consent and ethical approval of the 
c

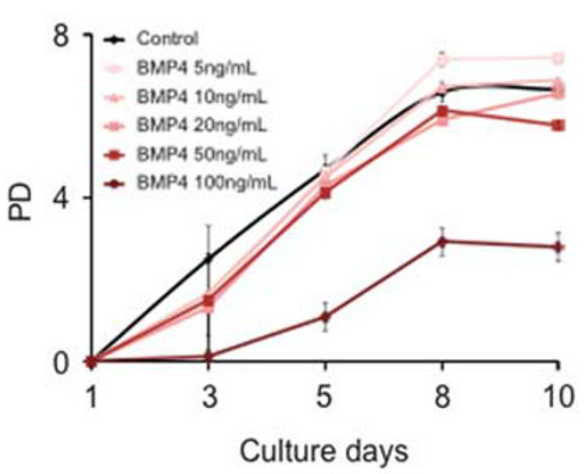

UTE
PL

d
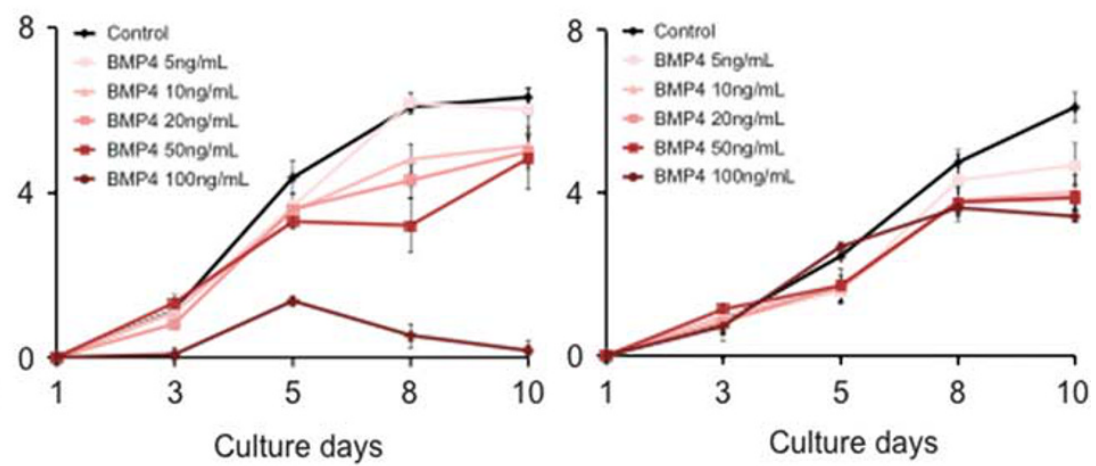

(\%)
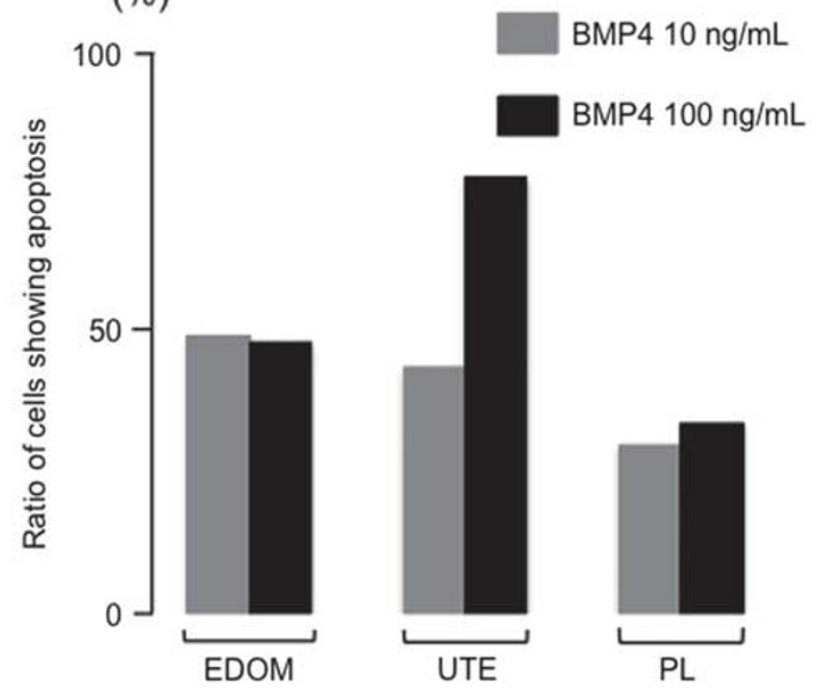

Figure 1 Continued.

Institutional Review Board of the National Institute for Child Health and Development, Japan (permit numbers EDOM no. 146, PL no. 55, and UTE no. 89). All experiments conducted in this study using human cells and tissues were performed in accordance with the tenets of the Declaration of Helsinki.

\section{Mouse Experiments}

All mouse experiments in this study were conducted according to protocols approved by the Institutional Animal Care and Use Committee of the NRICHD (Permit Number: A2016-003). Adult female B6D2F1 mice were purchased from Clea Japan (Tokyo, Japan) and oocytes were collected following standard methods. ${ }^{14}$ For functional assay of in vitro prepared human chorionic gonadotropin (HCG), pregnant mare serum gonadotropin (PMSG; 7.5 IU; Merck Millipore, Germany) was injected into the abdominal cavity followed by injection of the supernatant of BMP4-treated culture medium $(1.5 \mathrm{ml})$ within $48 \mathrm{~h}$. At $16 \mathrm{~h}$ after supernatant injection, the oviducts were retrieved and the presence of superovulation was confirmed by microscopy.

\section{hiPSC Culture and Differentiation into Trophoblast Lineages}

We used three types of hiPSCs that had been previously established: cells derived from menstrual blood (EDOM), placental artery endothelium (PL), and uterine endometrium (UTE). These lines were established by retroviral infection of four reprogramming factors (OCT-3/4, SOX2, c-MYC, and KLF4), and transgene silencing was confirmed. ${ }^{15}$

The hiPSCs were maintained on irradiated mouse embryonic fibroblasts in medium consisting of $80 \%$ KnockOut DMEM (ThermoFisher Scientific, Waltham, MA, USA), 20\% KnockOut Serum Replacement (ThermoFisher Scientific), $2 \mathrm{mM}$ L-glutamine (ThermoFisher Scientific), $100 \mathrm{U} / \mathrm{ml}$ penicillin (ThermoFisher Scientific), $100 \mu \mathrm{g} / \mathrm{ml}$ streptomycin (ThermoFisher Scientific), $0.1 \mathrm{mM}$ nonessential amino acids (ThermoFisher Scientific), $0.2 \mathrm{mM}$ 2-mercaptoethanol (Sigma, St Louis, MO, USA), and $10 \mathrm{ng} / \mathrm{ml}$ recombinant human bFGF (Wako Pure Chemical Industries, Osaka, Japan).

For trophoblast differentiation, CTK solution (Reprocell, Yokohama, Japan) was added for $1-2 \mathrm{~min}$ at room 


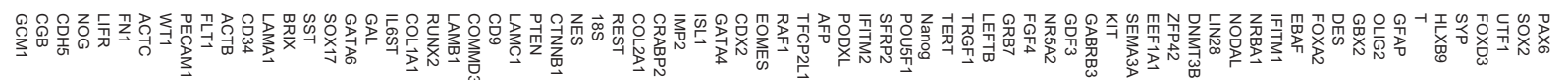

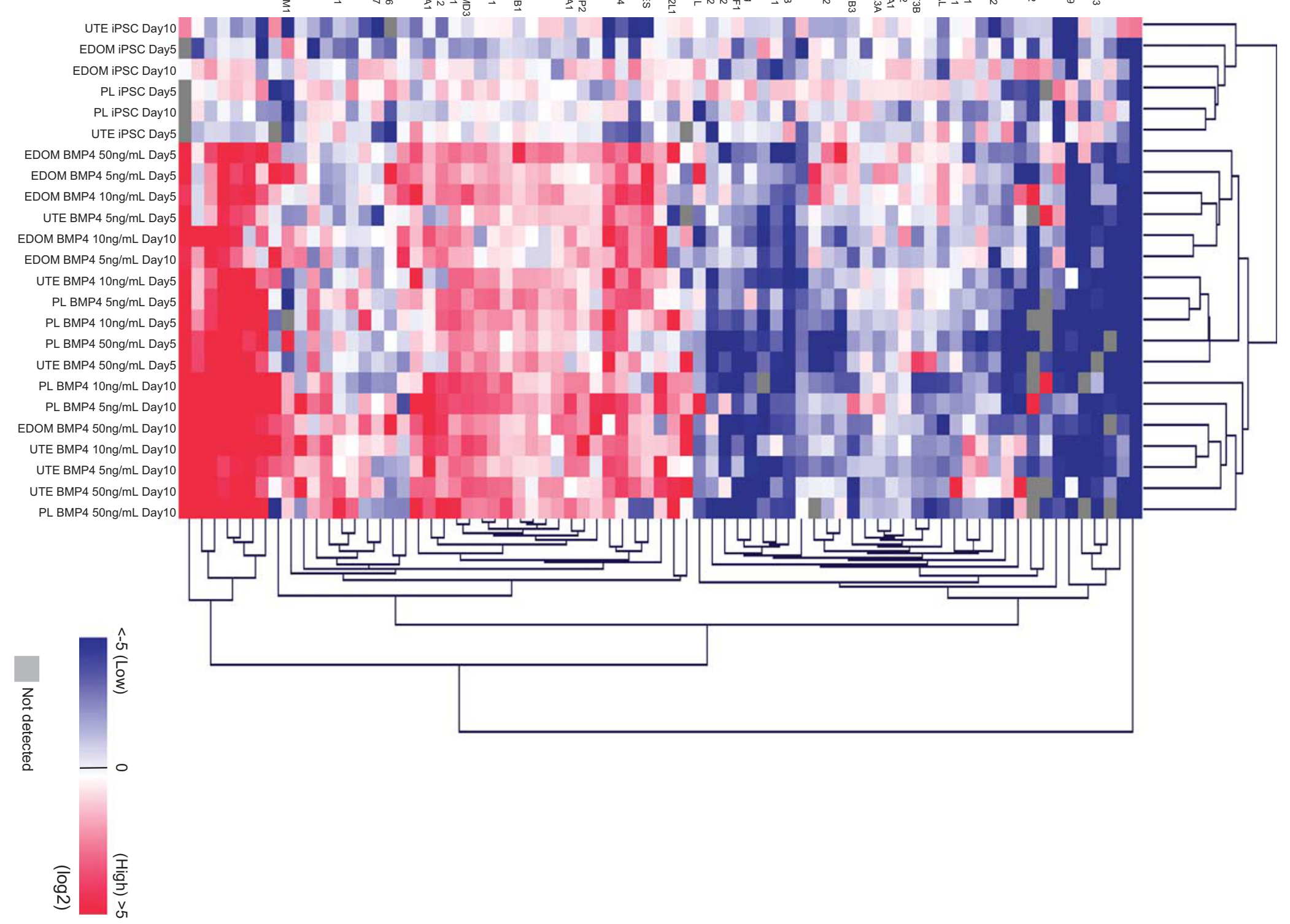


temperature to remove feeder cells. Next, hiPSCs were dissociated into single cells by treatment with $0.5 \times$ TrypLE Select $(1 \times$ TrypLE Select (ThermoFisher Scientific) diluted $1: 1$ with $0.5 \mathrm{mM}$ EDTA/PBS(-)) and passaged at $7.5 \times 10^{4}$ cells per well in six-well plates coated with $0.5 \mu \mathrm{g} / \mathrm{cm}^{2}$ laminin-511 E8 fragments (LN511E8; Nippi, Yokohama, Japan). Cells were cultured in StemFit medium (Ajinomoto, Tokyo, Japan), which contained only recombinant growth factor and protein, and were supplemented with $0,5,10,20$, 50, or $100 \mathrm{ng} / \mathrm{ml}$ carrier-free BMP4 (R\&D Systems, Minneapolis, MN, USA). ROCK inhibitor (Y-27632; Wako, Tokyo, Japan) at a final concentration of $10 \mu \mathrm{M}$ was used only at the time of plating, and the medium was changed the next day to fresh StemFit supplemented with BMP4 without the ROCK inhibitor. The medium was thereafter changed every day. Cells were maintained in culture for 10 days, and samples were harvested from $1,3,5,8$, and 10 days for analysis of differentiation.

\section{Gene Expression Assay}

Total RNA from cultured cells was extracted using an RNeasy Mini Kit or RNeasy Micro RNA Kit (Qiagen, Hilden, Germany) based on the manufacturer's instructions. Total RNA $(1 \mu \mathrm{g})$ was used for cDNA synthesis using SuperScript

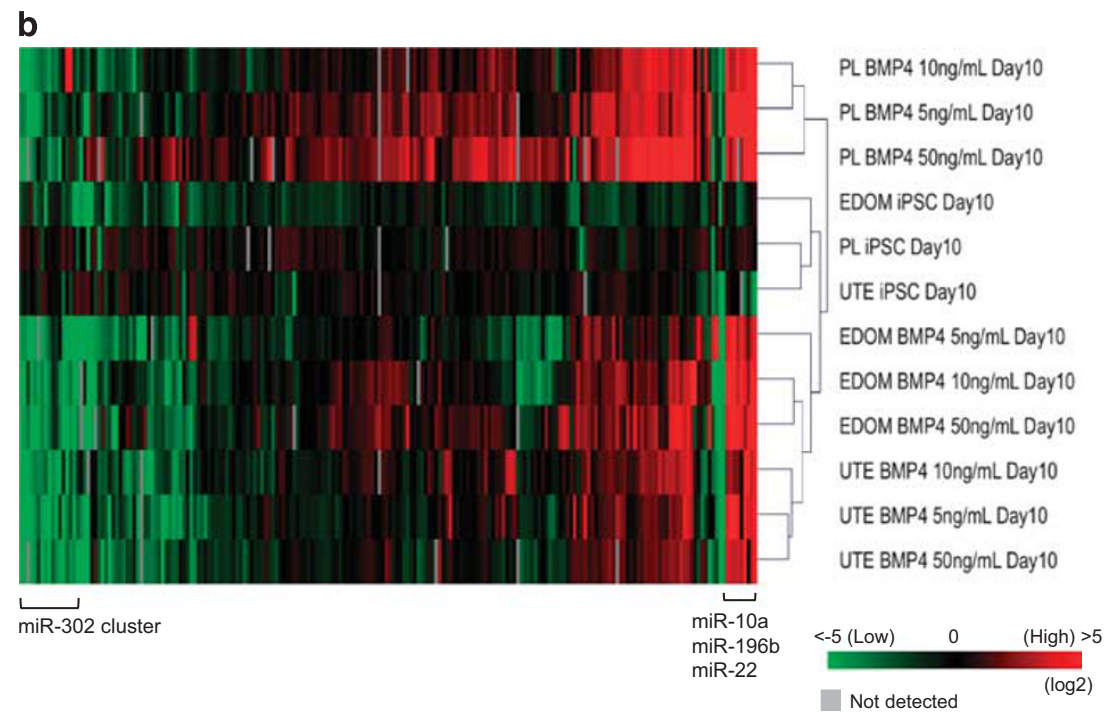

C

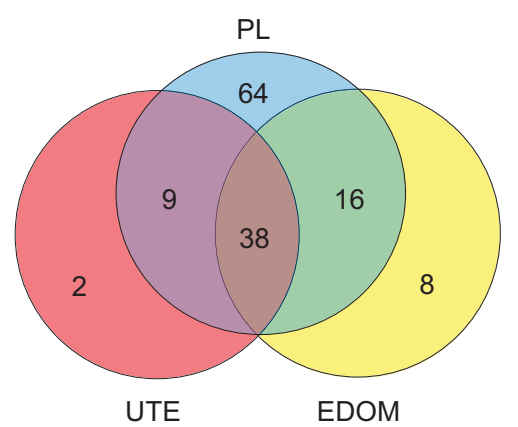

d Down-regulation

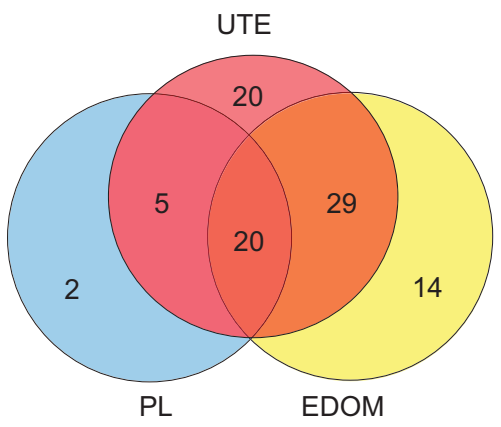

Figure 2 Continued.

Figure 2 Expression of pluripotency- and differentiation-related genes. (a) A heat map shows the average expression level of each gene from two independent experiments by TaqMan array. GAPDH was used as an internal control, and the expression level of each sample was normalized by the average expression level in hiPSCs. (b) miRNA expression profiles in hiPSCs and cells treated with BMP4 (5, 10, or $50 \mathrm{ng} / \mathrm{ml})$ at day 10 . A heat map shows the average expression level of each gene from two independent experiments by TaqMan MicroRNA array card A. U6 was used as an internal control, and the expression level of each sample was normalized by the average expression level in hiPSCs. (c and d) Venn diagram of differentially expressed miRNAs. The number of upregulated and downregulated miRNAs in BMP4-treated cells of each group are shown in panels (c) and (d), respectively. 


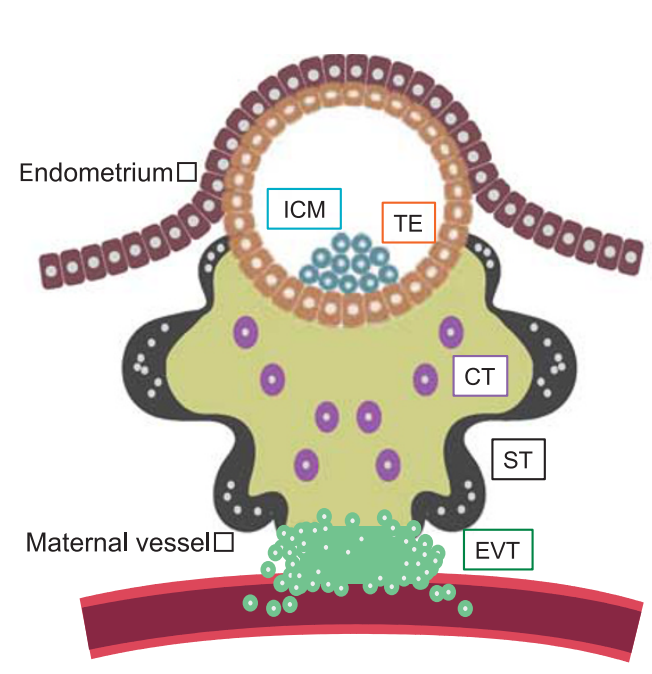

ICM : POU5F1

TE : CDX2 GATA3 KRT18 HAND1

TFAP2C EOMES GDF15 PPAR-Y

\section{CT : KRT7 KLF6}

ST : GCM1 Syncytin1 Syncytin2 CGA CGB

EVT : HLA-G

Others

Mature placental marker : PGF PAPP

Decidual marker : PIBF

TE: Trophectderm

ICM: Inner cell mass

CT: Cytotrophoblast

ST: Syncytiotrophoblast

EVT : Extra villous trophoblast
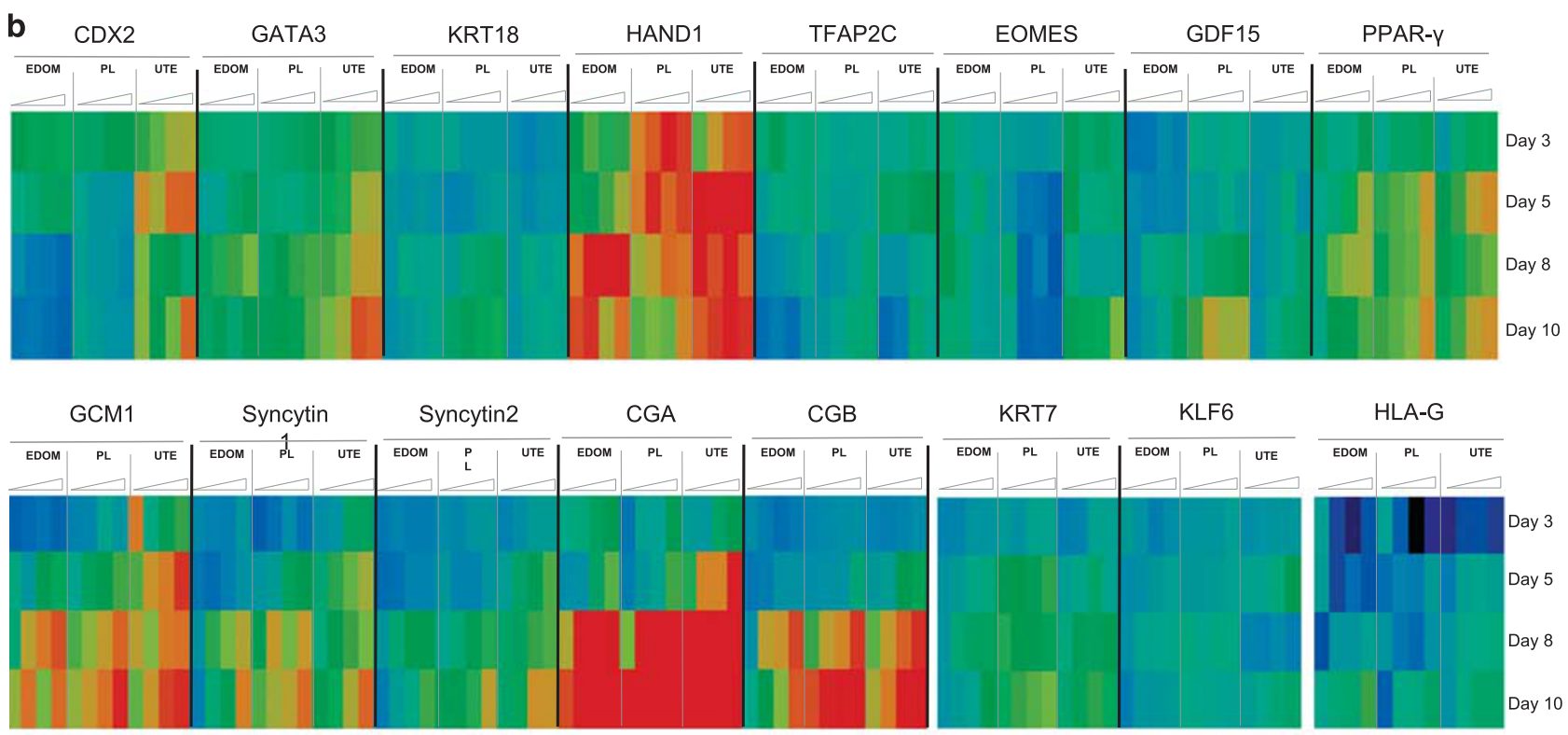

HLA-G
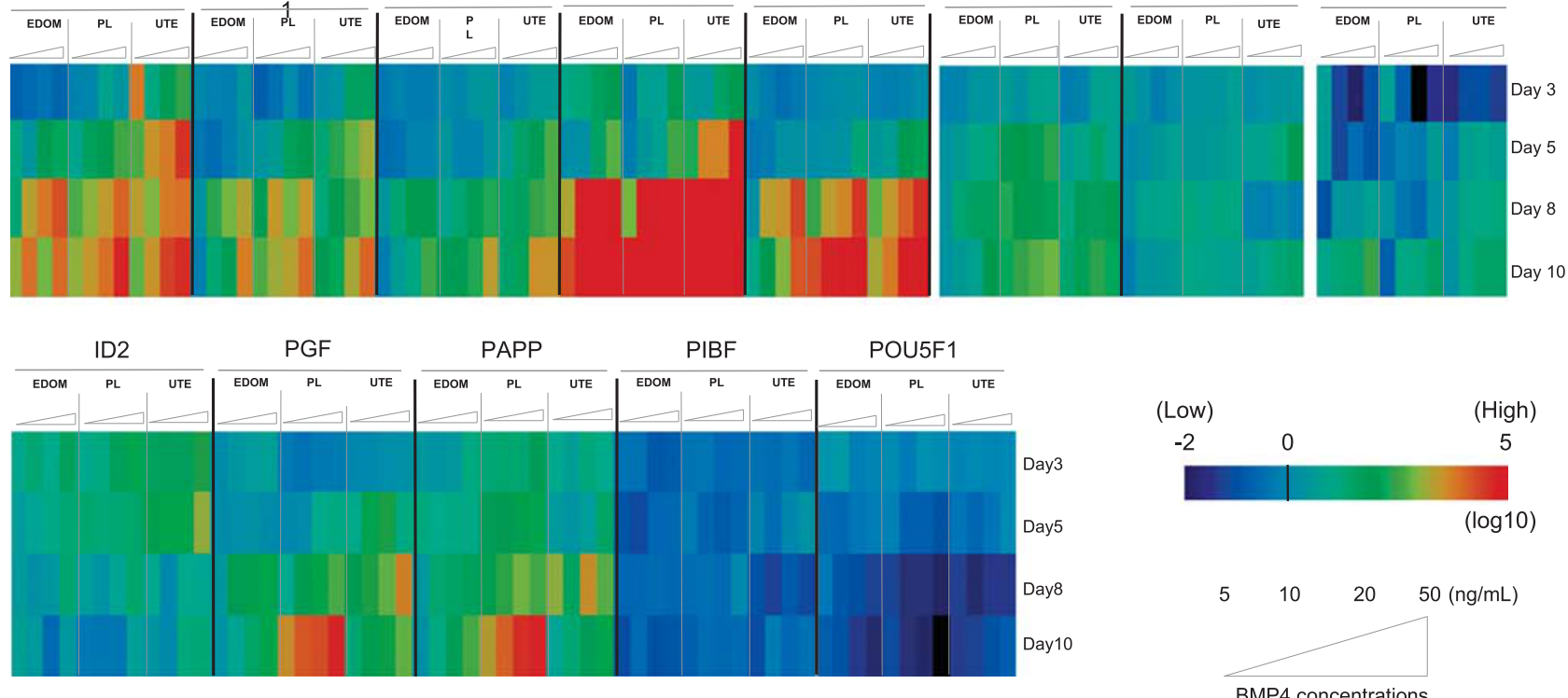

Figure 3 Effect of BMP4 dosage on the expression of trophoblast markers. (a) Scheme of trophoblast differentiation after implantation. All marker genes examined in this study are shown. The representative trophoblast markers are highlighted in bold. (b) Heat map showing the expression patterns of various trophoblast markers in cells treated with $5,10,20$, or $50 \mathrm{ng} / \mathrm{ml} \mathrm{BMP4}$ on days 3, 5, 8, or 10. GAPDH was used as an internal control, and the expression level of each sample was normalized by that of the parental hiPSC line. The average expression in two independent samples is shown for each marker. 
a

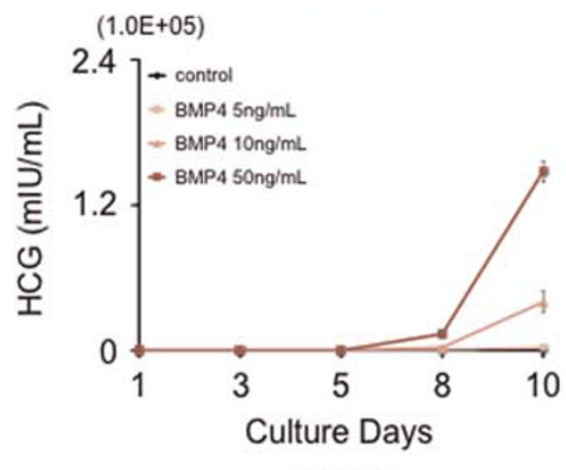

EDOM

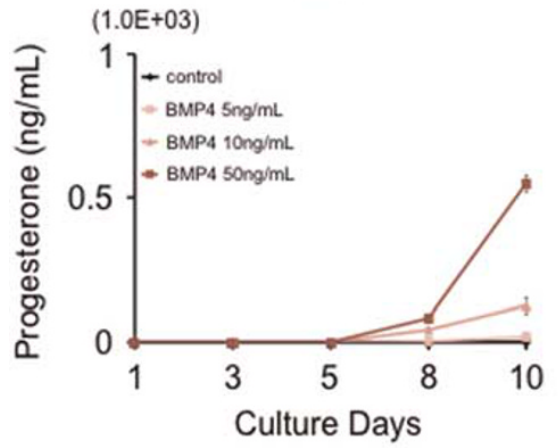

b

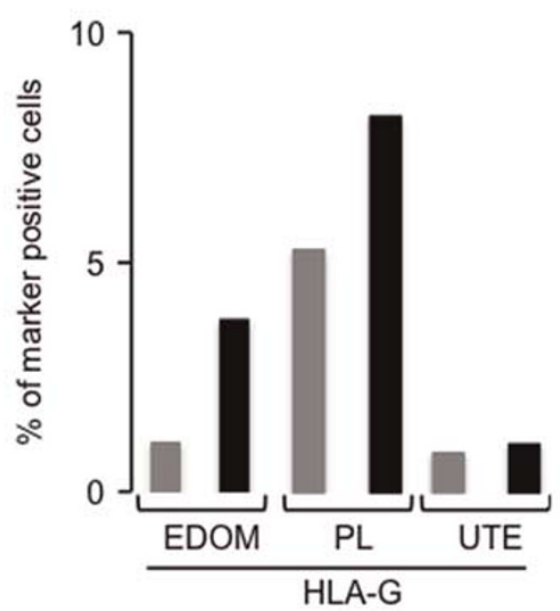

UTE
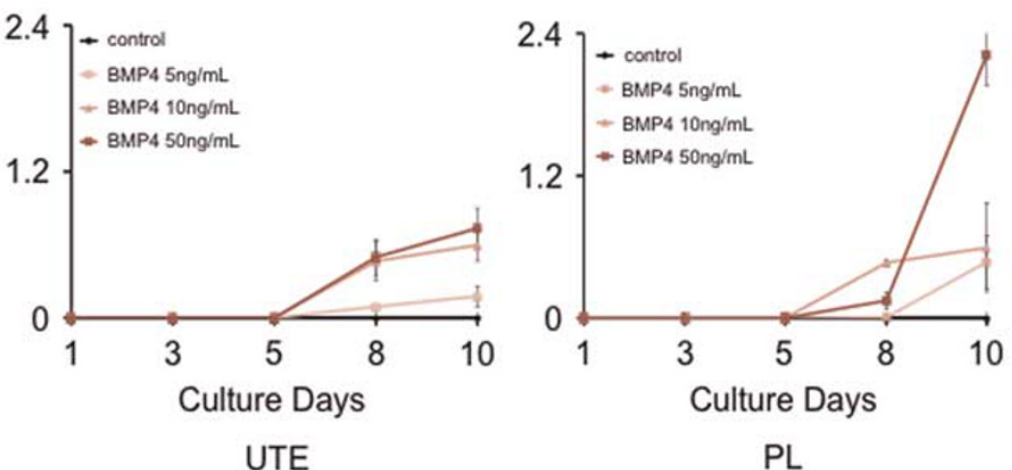

PL
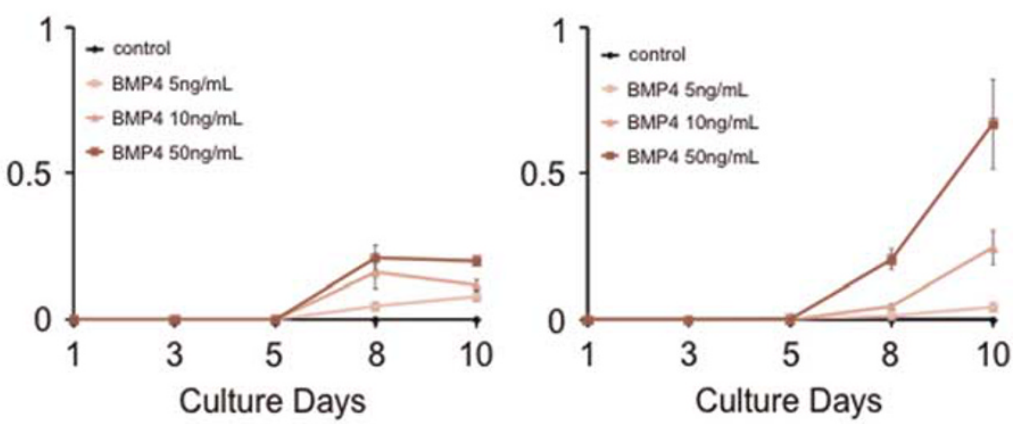

BMP4 $10 \mathrm{ng} / \mathrm{mL}$

BMP4 $50 \mathrm{ng} / \mathrm{mL}$

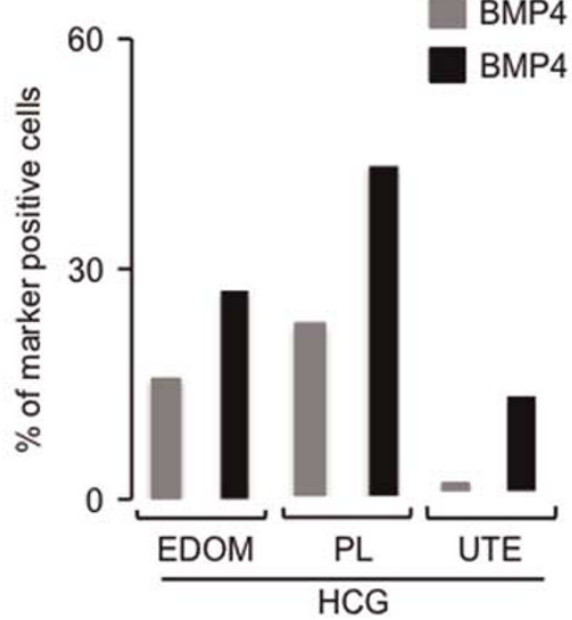

Figure 4 Effect of HCG and HLA-G expression states at single-cell resolution. (a) ELISA assay of HCG and P4 using culture supernatants. Three independent experiments were performed. Error bars show s.e. (b) FC analysis of HCG or HLA-G in cells treated with 10 or $50 \mathrm{ng} / \mathrm{ml}$ BMP4 at day 10 . The percentages represent average ratios of marker-positive cells from three independent experiments. (c) Immunofluorescence analysis of HCG and HLA-G in cells treated with $50 \mathrm{ng} / \mathrm{ml} \mathrm{BMP4}$ at day 10. White (DAPI), red (HCG), and green (HLA-G). Scale bar $=50 \mu \mathrm{m}$.

III (ThermoFisher Scientific). cDNA was used for TaqMan gene expression analysis. The primers used in this study are shown in Supplementary Table S1. For normalization, $G A P D H$ was used as an internal control in the TaqMan array (and individual TaqMan probe assay). Genes that were clearly detected in two experiments were used for the assay.

For miRNA detection, a miRNeasy Micro Kit (Qiagen) was used for extraction of RNA and cDNA synthesis according to the manufacturer's instructions. miRNA was analyzed using a
TaqMan Human MicroRNA array card A (ThermoFisher Scientific). U6 was used as an internal control.

\section{Immunofluorescence}

Cells were cultured in a glass-bottom dish (IWAKI, Japan) and fixed with $4 \%$ paraformaldehyde for 10 min before being permeabilized with $0.1 \%$ Triton X-100 (Sigma) for $10 \mathrm{~min}$. After blocking with $1 \%$ normal goat serum in phosphatebuffered saline (PBS) for $30 \mathrm{~min}$, the samples were incubated 
C

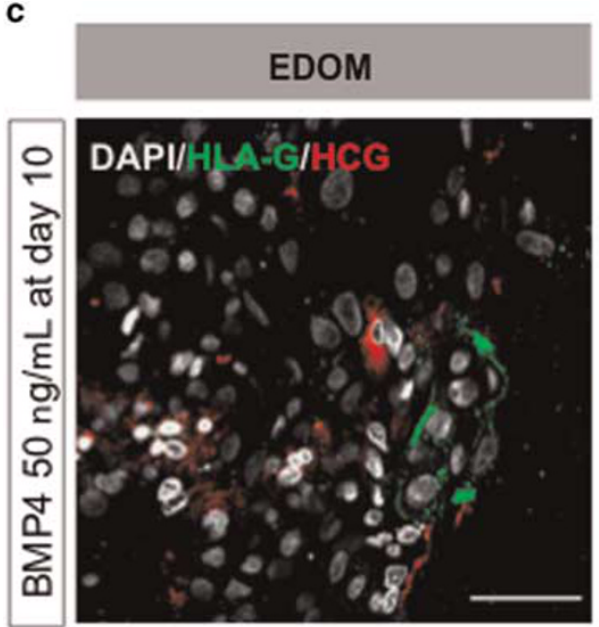

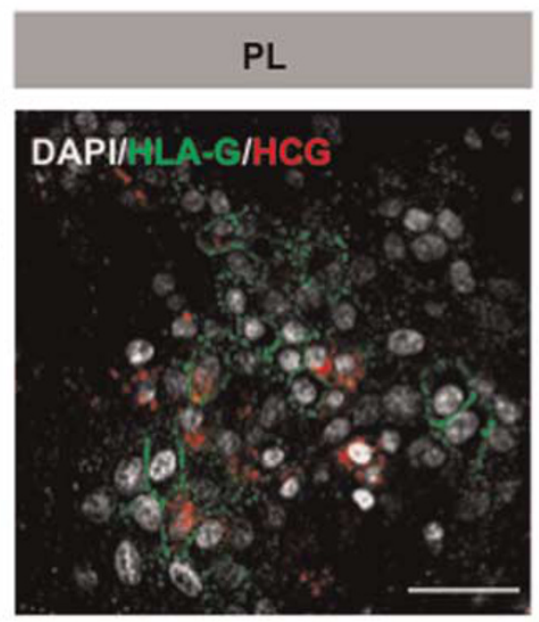

Figure 4 Continued.

with primary antibodies at $4{ }^{\circ} \mathrm{C}$ overnight. After washing with PBS, the samples were incubated with secondary antibodies conjugated with Alexa 488 or 546 (Alexa Fluor, Invitrogen, Carlsbad, CA) for $30 \mathrm{~min}$. Finally, the cells were stained for nuclei and mounted with VECTASHIELD (Vector Laboratories, Burlingame, CA, USA). Primary antibodies used in this study were OCT4 (C-10; Santa Cruz Biotechnology, Dallas, TX, USA, 1:300), NANOG (Reprocell, 1:300), HCG (ab9376; Abcam, Cambridge, MA, USA, 1:100), and HLA-G (ab7758; Abcam, 1:50). Images were obtained using an LSM510 laser scanning confocal microscope (Carl Zeiss, Oberkochen, Germany).

\section{Detection of Cell Apoptosis by Annexin V Staining}

Apoptosis was assessed with bivariate annexin V/7-aminoactinomycin D analysis. Cells were cultured in six-well plates and treated with 10 or $100 \mathrm{ng} / \mathrm{ml} \mathrm{BMP} 4$ for 10 days. Cells undergoing apoptosis at the indicated time were identified using the Muse Annexin V and Dead Cell Assay (Merck Millipore), following the manufacturer's instructions.

\section{Chemiluminescence Enzyme Immunoassay and Electrochemiluminescence Immunoassay of Placental Hormones in the Culture Medium}

The hiPSCs (EDOM, PL, and UTE) were treated as above. One milliliter of medium was collected on $1,3,5,8$, and 10 days. HCG- $\beta$ concentrations were measured using the IMMULITE 2000 XPi Immunoassay System (Siemens Healthcare, Germany), and progesterone concentrations were measured using MODULAR ANALYTICS (Roche Diagnostics, JAPAN), according to the manufacturers' protocols. Each assay was performed in triplicate.

\section{Flow Cytometry (FC)}

Cells were disassociated into single cells with Accutase (ThermoFisher Scientific). For HCG detection, the cells were filtered through a $100-\mu \mathrm{m}$ cell strainer, fixed with $0.2 \%$ paraformaldehyde for $10 \mathrm{~min}$, and permeabilized with $0.1 \%$ Triton X-100 (Sigma) for $10 \mathrm{~min}$ at room temperature. After washing with PBS, cells were incubated with HCG (ab9582; Abcam, 1:400) in 3\% bovine serum albumin with PBS for $40 \mathrm{~min}$ at room temperature. Cells were then incubated with a fluorescent secondary antibody for $30 \mathrm{~min}$ at room temperature, and an SH800Z cell sorter (Sony, Tokyo, Japan) was used for detection.

For HLA-G and KRT7 detection, fixation and permeabilization procedures were omitted. After disassociation, cells were filtered through a $40-\mu \mathrm{m}$ cell strainer. Cells were incubated with HLA-G (ab7758; Abcam, 1:50) or KRT7 (ab9021; Abcam, 1:100) for $40 \mathrm{~min}$ at room temperature. After washing with PBS, samples were incubated with a fluorescent secondary antibody for $30 \mathrm{~min}$ at room temperature. After washing, an Attune Acoustic Focusing Cytometer (ThermoFisher Scientific) was used for detection. The same experiment was conducted without the primary antibody for negative control samples.

\section{Chromatin Immunoprecipitation Followed by qPCR (ChIP-qPCR)}

ChIP-qPCR was carried out based on previous methods. ${ }^{14}$ In brief, chromatin from $5 \times 10^{6}$ iPSCs was prepared for ChIP with antibodies against $\mathrm{H} 3$ (Abcam: ab1791), H3K4me3 (Abcam: ab8580), H3K27me3 (Millipore: 07-449), and IgG (Abcam: ab37415). The iQ SYBR green super mix (Bio-Rad) was used for qPCR. Primers used in the assay are provided in Supplementary Table S2.

\section{RESULTS}

Effect of BMP4 Dosage on Cellular Proliferation

We used three types of hiPSCs that had been previously established: cells derived from menstrual blood (EDOM), placental artery endothelium (PL), and uterine endometrium 
a

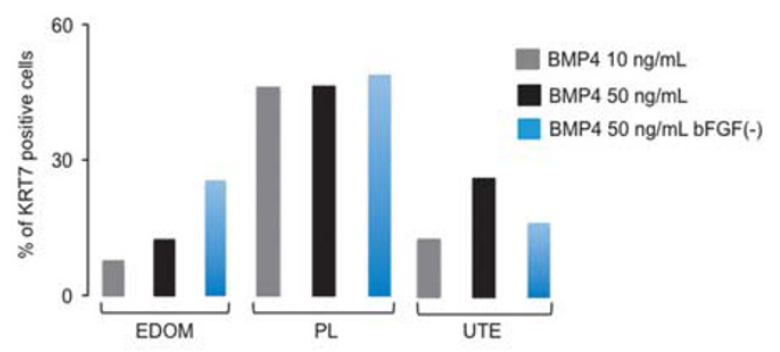

b

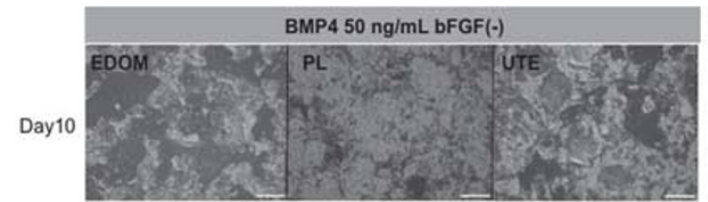

C
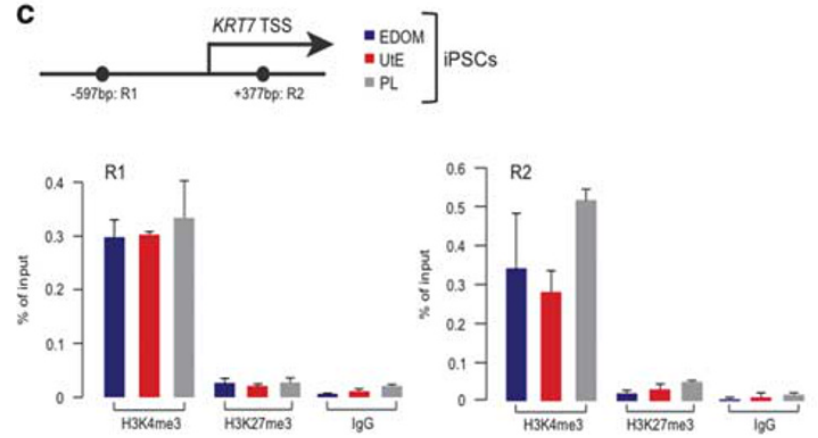

Figure 5 Ability of hiPSCs to differentiate into KRT7+ cells. (a) FC analysis of KRT7 in cells treated with $10 \mathrm{ng} / \mathrm{ml} \mathrm{BMP4}$ (bFGF+) and $50 \mathrm{ng} / \mathrm{ml} \mathrm{BMP4}$ (bFGF+ or bFGF - ) at day 10. Three independent experiments were conducted; the percentages represent average ratios of marker-positive cells. (b) Morphology of cells treated with $50 \mathrm{ng} / \mathrm{ml}$ BMP4 (bFGF - ). Scale bar $=500 \mu \mathrm{m}$. (c) ChIP-qPCR analysis of H3K4me3 and H3K27me3 in KRT7 promoter regions in hiPSCs. Two independent experiments were carried out. Error bars show s.e.

(UTE). ${ }^{15}$ Immunofluorescence analysis revealed normal expression of OCT4 and NANOG pluripotency markers in all types of hiPSCs (Figure 1a). To remove the effect of feeder cells on BMP4-induced trophoblast differentiation, we used StemFit medium to induce trophoblast differentiation, allowing for the easy maintenance of hiPSCs in feeder-free conditions with high reproducibility. ${ }^{16}$ First, we examined whether BMP4 concentration affected cellular viability during trophoblast differentiation of hiPSCs. Each hiPSC type was allowed to differentiate in the presence of 10,50 , or $100 \mathrm{ng} / \mathrm{ml}$ BMP4 for 10 days without feeder cells. At day 8, obvious morphological changes were observed in all cell types treated with 10 or $50 \mathrm{ng} / \mathrm{ml} \mathrm{BMP4}$ (Figure 1b). For EDOM and UTE cell types, the differentiating cells did not appear to proliferate following treatment with $100 \mathrm{ng} / \mathrm{ml}$ BMP4 (Figure 1b). Analysis of population doublings (PDs) of differentiating cells with various concentrations of BMP4 $(5,10,20,50$, and $100 \mathrm{ng} / \mathrm{ml}$ ) exhibited that $100 \mathrm{ng} / \mathrm{ml}$ BMP4 treatment attenuated cellular proliferation in these cell types (Figure 1c). Notably, the PD of PL-hiPSCs was slower than the PDs of other cell lines (Figure 1c), implying that delayed morphological changes of PL cells treated with BMP4 is attributed to the hiPSC type itself.

In order to examine cellular physiological changes at day 10 in cells treated with $100 \mathrm{ng} / \mathrm{ml} \mathrm{BMP4}$, we examined apoptosis states in all types of differentiating cells. Annexin $\mathrm{V}$ assay revealed that apoptotic cells increased 1.8-fold among UTE cells treated with $100 \mathrm{ng} / \mathrm{ml}$ BMP4 (Figure 1d). Interestingly, other BMP4-treated cells did not exhibit increased apoptosis (Figure 1d), implying that induction of apoptosis depends on hiPSC type. Taken together, these experiments suggested that high doses of BMP4 are harmful for cellular viability and that there is an optimal BMP4 concentration for induction of cellular differentiation.

\section{Effects of BMP4 Treatment on Expression of Pluripotency- and Differentiation-Related Genes and miRNAs}

Next, in order to examine the effect of BMP4 dosage on gene expression, we conducted a gene expression assay using TaqMan pluripotent stem cell array, a high-fidelity method for quantitative gene expression. The assay includes the major transcription factors associated with pluripotency and various differentiation-related genes. ${ }^{17}$ The three hiPSC types were allowed to differentiate for 5 or 10 days in the presence of 5 , 10 , or $50 \mathrm{ng} / \mathrm{ml} \mathrm{BMP} 4$. Out of the 96 genes assayed, 75 genes (excluding XIST, which exhibits female-specific expression) passed filtering criteria and were used for clustering analysis based on gene expression states. Intriguingly, hierarchical clustering of BMP4-treated cells on day 10 was not based on hiPSC type; rather, samples were divided into groups based on treatment conditions. For example, the expression patterns on day 10 of cells treated with $50 \mathrm{ng} / \mathrm{ml}$ BMP4 were similar to each other (Figure 2a), implying that long-term culture with a high concentration of BMP4 results in common differentiation patterns. In contrast, on day 5, EDOM and PL cells were each categorized into their own cluster (Figure 2a), suggesting that BMP4 treatment does not greatly affect gene expression states in the early phases of differentiation. At this phase, the type of hiPSC or genetic background may provide the dominant influence on expression.

Gene expression clustering revealed that BMP4 treatment led to downregulation of pluripotency-related factors, such as OCT4 and NANOG, ${ }^{18}$ and activation of genes related to cellular adhesion, such as CDH5, FN1, and LAMB1 (Figure 2a). This reflects the fact that BMP4 treatment of hiPSCs induces epithelial-mesenchymal transition. ${ }^{19}$ Extraembryonic markers (CDX2 and EOMES) and trophoblast markers (CGB and GCM1) were also upregulated (Figure 2a) with BMP4 treatment. Finally, we found that FOXD3 expression levels were reduced compared with those of hiPSCs (Figure 2), suggesting that BMP4-treated cells differentiate toward the endoderm and mesoderm lineages, ${ }^{20}$ in addition to the trophoblast lineage. 
A recent study showed that some miRNA families serve as placental markers. ${ }^{21,22}$ As the above results indicated that long-term culture with high doses of BMP4 induced similar gene expression states among differentiated cells, we examined miRNA expression states in hiPSCs and cells treated with BMP4 $(5,10$, or $50 \mathrm{ng} / \mathrm{ml})$ for 10 days using a TaqMan Human MicroRNA array card A, on which the placentarelated genes were mapped. Following the assay of 208 expressed miRNAs, we conducted hierarchical clustering analysis. Surprisingly, unlike protein-coding genes, the expression levels of BMP4-treated cells were dependent on cell types rather than culture conditions (Figure $2 \mathrm{~b}$ ). Interestingly, the number of upregulated miRNAs (defined in all types of cells as a $>2$-fold change $v s$ control hiPSCs) was higher in PL cells (127 genes) than in EDOM (62 genes) or UTE cells (49 genes) (Figure 2c). In contrast, PL cells exhibited fewer downregulated miRNAs (Figure 2d). We also identified commonly upregulated miRNAs in all cell types, such as miRNA-196b, miRNA-10a, and miRNA-22. Although these genes have not been previously reported to be associated with placentation, expression of these genes is involved in cancer cells.

Taken together, these results indicated that the transcriptional states of protein-coding genes in BMP4-induced trophoblast cells are dependent on culture conditions, while those of miRNAs are affected by cell type.

\section{In-Depth Expression Analysis of Trophoblast Markers Following BMP4 Treatment}

In order to gain further insight into the dose-dependent effects of BMP4 on trophoblast differentiation, we examined the expression patterns of 16 trophoblast lineage markers and 5 non-trophoblast markers (all protein-coding genes) following treatment with various BMP4 concentrations $(5,10,20$, and $50 \mathrm{ng} / \mathrm{ml}$ ) for varying lengths of time $(3,5,8$, and 10 days) (Figure 3a). To minimize the effects of genetic variation and cell type on gene expression, the expression levels in each BMP4-treated cell type were normalized to the expression levels in the parental cell type. Expression levels of cytotrophoblast markers (KRT7 and KLF6), syncytiotrophoblast markers (GCM1, SYNCYTIN1/2, CGA, and CGB), and extravillous trophoblast marker $(H L A-G)$ were altered in a dose-dependent manner following BMP4 treatment (Figure $3 \mathrm{~b}$ ). Most trophectoderm and trophoblast markers exhibited dose-dependent expression as well (Figure 2a). Consistent with a previous report, ${ }^{23} \mathrm{CDX} 2$ expression levels were high at day 3 in EDOM and PL cells under most doses of BMP4. However, CDX2 levels in UTE cells and HAND1 in PL cells were not downregulated during differentiation (Figure $3 \mathrm{~b}$ ). In contrast, TFAP2C appeared to be downregulated in EDOM and UTE cells with BMP4 treatment (Figure 3b). These results suggested that hiPSC type influences the response to BMP4.

We also found that several trophectoderm markers, including GDF15, TFAP2C, HAND1, and PPAR- $\gamma$, were upregulated by BMP4 treatment in a dose-dependent manner (Figure $3 \mathrm{~b}$ ). As expected, the decidua marker PIBF was not nearly expressed in BMP4-treated cells (Figure 3b). We also examined the expression levels of the mature placental markers PGF and PPAP. The expression levels of both genes increased as the period of exposure to BMP4 increased in all cell types (Figure $3 \mathrm{~b}$ ). Taken together, these data indicate that BMP4 treatment of hiPSCs robustly induces the expression of markers of the trophoblast lineage in a dose-dependent manner.

\section{Effect of BMP4 Dosage on HLA-G and HCG Expression States at Single-Cell Resolution}

HCG and progesterone are thought to be definite placental markers. ${ }^{24-26}$ Enzyme-linked immunosorbent assay demonstrated that our differentiation conditions produced high levels of HCG and progesterone proteins according to BMP4 dosage in all cell types (Figure 4a). Moreover, in vitroproduced HCG induced ovulation in mice (Supplementary Figure S1), indicating that the HCG derived from hiPSCs was functional.

Next, to investigate the effects of BMP4 dosage at single-cell resolutions on trophoblast lineage differentiation, we evaluated the protein expression of HCG and HLA-G by FC analysis. We treated cells with 10 or $50 \mathrm{ng} / \mathrm{ml}$ BMP4 for 10 days to examine the effect of BMP4 dosage. In EDOM and PL cells, BMP4 treatment elicited dose-dependent upregulation of these proteins, as follows: HLA-G and HCG were upregulated 3.5- and 1.8-fold ( $10 v s 50 \mathrm{ng} / \mathrm{ml})$, respectively, in EDOM cells, and HLA-G and HCG were upregulated 1.5- and 1.9-fold ( $10 v s 50 \mathrm{ng} / \mathrm{ml}$ ), respectively, in PL cells (Figure 4b). In UTE cells, although HCG expression states were affected by BMP4 dosage (12-fold up in $50 \mathrm{ng} / \mathrm{ml}$ ), there was no dose effect on HLA-G expression states (Figure 4b).

We also investigated whether BMP4 treatment in high doses produced cells doubly positive for HCG and HLA-G expression. To examine this, we carried out immunofluorescence analysis with dual staining for HCG and HLA-G. As shown in Figure 4c, we did not find cells with both markers but instead found that most cells expressed either HCG or HLA-G. Thus treatment of hiPSCs with BMP4 accurately produced several types of trophoblast cells. These results indicated that BMP4 treatment of various types of hiPSC lines increases the proportion of cells expressing trophoblast markers in a dose-dependent manner.

\section{Ability of hiPSCs to Differentiate into KRT7-Expressing Cells}

In trophoblast differentiation, KRT7 has been used as a marker for cytotrophoblasts. ${ }^{27}$ In order to examine whether our differentiation system could induce dose-dependent differentiation of cells expressing KRT7, we performed FC analysis using KRT7 antibody. Notably, FC analysis revealed that the proportion of $\mathrm{KRT}^{+}$cells was the same at all doses of 
BMP4 in PL cells, while it increased with increasing BMP4 dosage in EDOM and UTE cells (10 vs $50 \mathrm{ng} / \mathrm{ml}$; Figure 5a).

However, the trophoblast differentiation system used in this study contained bFGF, an essential factor for maintaining primed states in hPSCs. ${ }^{2,3}$ A recent study showed that the absence of bFGF increases KRT7 expression levels. ${ }^{6}$ Thus we tested whether the removal of bFGF during BMP4 treatment would result in efficient induction of $\mathrm{KRT}^{+}$cells. At day 10, as expected, the removal of bFGF resulted in the effective induction of $\mathrm{KRT7}^{+}$EDOM cells (Figure 5a). In PL cells, the removal of bFGF did not seem to affect differentiation (Figure 5a). This may result from the fact that PL cells exhibited a high proportion of $\mathrm{KRT7}^{+}$cells even with a low dose of BMP4. Intriguingly, bFGF removal prevented UTEhiPSCs from differentiating into $\mathrm{KRT7}^{+}$cells (Figure 5a). The proportion of $\mathrm{KRT}^{+}$cells was comparable between the BMP4 (50 ng/ml)/bFGF( - ) and BMP4 (10 ng/ml)/bFGF(+) treatments (Figure 5a). Thus removal of bFGF did not essentially improve the derivation efficiency of $\mathrm{KRT}^{+}$cells.

Finally, to investigate the molecular mechanisms underlying differentiation potency, we determined chromatin states in KRT7 promoter regions. ChIP-qPCR against H3K4me3 and $\mathrm{H} 3 \mathrm{~K} 27 \mathrm{me} 3$, which are transcriptionally active and repressive marks, respectively, was carried out in the three hiPSC lines. The results showed comparable states across the three iPSCs (Figure 5c), indicating that epigenetic states at KRT7 promoter regions do not directly affect transcriptional potency.

\section{DISCUSSION}

In this study, we used a high-fidelity gene expression assay to examine the expression profiles of three types of hiPSCs treated with various doses of BMP4. We found that an excess amount of BMP4 negatively affected cellular viability and that an optimal concentration exists for trophoblast differentiation. Notably, the expression levels of several trophoblastrelated genes exhibited BMP4 dose dependency. Thus our findings provide information that should be useful for the generation of patient-specific trophoblast cells from hiPSCs. However, some of our gene expression findings differ from those of previous studies. Sudheer et $a l^{6}$ and Amita et al $l^{11}$ reported that SOX2 and EOMES were not detectable during the trophoblast differentiation process. In our study, while the SOX2 expression pattern was consistent with these previous studies (Figure 2a), we found that EOMES expression was upregulated on day 10 in UTE cells treated with $50 \mathrm{ng} / \mathrm{ml}$ BMP4 (Figure 3b). Therefore, the expression levels of some genes may depend on detection system or differentiation conditions, such as the culture medium and/or cell lines.

In this study, we identified highly expressed miRNAs in BMP4-treated cells, such as miRNA-196b and miRNA-10a (Figure $2 \mathrm{~b}$ ). However, these genes were not highly expressed in previous studies using in vivo-derived placental cells. ${ }^{22}$ Therefore, these markers may be specific for cells derived from hiPSCs in vitro. As we could not determine whether the differential expression states of miRNAs were the cause or consequence of variations in differentiation potency, we can only state that miRNA expression may be a parameter for trophoblast differentiation from hiPSCs.

Single-cell analysis using FC revealed that the proportions of cells expressing HCG were increased by treatment with a high dose of BMP4 (Figure 4b). These results imply that trophoblast lineage differentiation is stochastic. Unlike HCG, induction of HLA-G-positive cells was not dose dependent in UTE cells only. Given that increases in UTE cells positive for KRT7, which serves as a pantrophoblast marker, were dose dependent (Figure 4a), these results imply that treatment with high doses of BMP4 would result in syncytiotrophoblast differentiation rather than extravillous cytotrophoblast differentiation in UTE cells.

In UTE cells, removal of bFGF with high doses of BMP4 led to a reduction in the population of $\mathrm{KRT}^{+}$cells (Figure 4a). This observation was in contrast to that of EDOM cells, where the removal of bFGF increased the proportion of $\mathrm{KRT}^{+}$cells. One possibility for this difference is that UTE-hiPSCs may react rapidly to the loss of bFGF and differentiate into other, non-trophoblast cells, as KRT7 was expressed in several epithelial cell types. ${ }^{28}$

With regard to trophoblast differentiation potency, we could not eliminate the possibility that epigenetic states were different among hiPSCs. However, ChIP-qPCR analysis showed that the KRT7 promoter regions were comparable among hiPSC types. These results imply that there may be cell type-specific roadblocks to KRT7 expression. These obstacles were partially eliminated by the removal of bFGF in EDOM cells, suggesting that bFGF removal does not always direct trophoblast differentiation. The bFGF pathway regulates pluripotency via activin and SMAD2/3 signals in hPSCs..$^{29,30}$ Moreover, bFGF prevents trophectoderm differentiation. ${ }^{6,7}$ Given that the genetic background determines transcriptional states in hPSCs, pluripotency states maintained by the bFGF pathway may differ among hiPSCs.

In summary, we revealed that there are optimal conditions for trophoblast differentiation from hiPSCs. Our results will aid in the production of patient-specific trophoblast cells from hiPSCs.

Supplementary Information accompanies the paper on the Laboratory Investigation website (http://www.laboratoryinvestigation.org)

\section{ACKNOWLEDGMENTS}

This work was supported by the Ministry of Education, Culture, Sports, Science, and Technology (MEXT) of Japan; Ministry of Health, Labor, and Welfare (MHLW) to HA and AU; Grant-in-Aid for Scientific Research (21390456); JSTCREST to HA; and JSPS KAKENHI Grant-in-Aid for Challenging Exploratory Research (16K15716) to HA.

\section{DISCLOSURE/CONFLICT OF INTEREST}

The authors declare no conflict of interest. 
1. Park $\mathrm{IH}$, Arora $\mathrm{N}$, Huo $\mathrm{H}$, et al. Disease-specific induced pluripotent stem cells. Cell 2008;134:877-886.

2. Thomson JA, Itskovitz-Eldor J, Shapiro SS, et al. Embryonic stem cell lines derived from human blastocysts. Science 1998;282: $1145-1147$.

3. $\mathrm{Xu} \mathrm{RH}, \mathrm{Chen} \mathrm{X}$, Li DS, et al. BMP4 initiates human embryonic stem cell differentiation to trophoblast. Nat Biotechnol 2002;20:1261-1264.

4. Scifres CM, Nelson DM. Intrauterine growth restriction, human placental development and trophoblast cell death. J Physiol 2009:587(Pt 14):3453-3458.

5. Fisher $\mathrm{SJ}$. Why is placentation abnormal in preeclampsia? Am J Obstet Gynecol 2015;213(4 Suppl):S115-S122.

6. Sudheer S, Bhushan R, Fauler B, et al. FGF inhibition directs BMP4mediated differentiation of human embryonic stem cells to syncytiotrophoblast. Stem Cells Dev 2012;21:2987-3000.

7. Das P, Ezashi T, Schulz LC, et al. Effects of fgf2 and oxygen in the bmp4-driven differentiation of trophoblast from human embryonic stem cells. Stem Cell Res 2007;1:61-74.

8. Miyazono K, Kamiya $\mathrm{Y}$, Morikawa M. Bone morphogenetic protein receptors and signal transduction. J Biochem 2010;147:35-51.

9. Hjertner $\mathrm{O}$, Hjorth-Hansen $\mathrm{H}$, Borset $\mathrm{M}$, et al. Bone morphogenetic protein-4 inhibits proliferation and induces apoptosis of multiple myeloma cells. Blood 2001;97:516-522.

10. Bernardo AS, Faial T, Gardner $L$, et al. BRACHYURY and CDX2 mediate BMP-induced differentiation of human and mouse pluripotent stem cells into embryonic and extraembryonic lineages. Cell Stem Cell 2011;9: 144-155.

11. Amita $\mathrm{M}$, Adachi $\mathrm{K}$, Alexenko $\mathrm{AP}$, et al. Complete and unidirectional conversion of human embryonic stem cells to trophoblast by BMP4. Proc Natl Acad Sci USA 2013;110:E1212-E1221.

12. Chen Y, Wang K, Chandramouli GV, et al. Trophoblast lineage cells derived from human induced pluripotent stem cells. Biochem Biophys Res Commun 2013;436:677-684.

13. Choi J, Lee $\mathrm{S}$, Mallard W, et al. A comparison of genetically matched cell lines reveals the equivalence of human iPSCs and ESCs. Nat Biotechnol 2015;33:1173-1181.

14. Fukuda A, Tomikawa J, Miura $\mathrm{T}$, et al. The role of maternal-specific H3K9me3 modification in establishing imprinted X-chromosome inactivation and embryogenesis in mice. Nat Commun 2014;5:5464.

15. Nishino K, Toyoda $M$, Yamazaki-Inoue $M$, et al. DNA methylation dynamics in human induced pluripotent stem cells over time. PLoS Genet 2011;7:e1002085.
16. Nakagawa $\mathrm{M}$, Taniguchi $\mathrm{Y}$, Senda $\mathrm{S}$, et al. A novel efficient feeder-free culture system for the derivation of human induced pluripotent stem cells. Sci Rep 2014;4:3594.

17. International Stem Cell Initiative, Adewumi O, Aflatoonian $B$, et al. Characterization of human embryonic stem cell lines by the International Stem Cell Initiative. Nat Biotechnol 2007:25:803-816.

18. Takahashi K, Yamanaka S. Induction of pluripotent stem cells from mouse embryonic and adult fibroblast cultures by defined factors. Cell 2006;126:663-676.

19. Richter A, Valdimarsdottir L, Hrafnkelsdottir HE, et al. BMP4 promotes EMT and mesodermal commitment in human embryonic stem cells via SLUG and MSX2. Stem Cells 2014;32:636-648.

20. Arduini BL, Brivanlou AH. Modulation of FOXD3 activity in human embryonic stem cells directs pluripotency and paraxial mesoderm fates. Stem Cells 2012;30:2188-2198.

21. Doridot L, Miralles F, Barbaux S, et al. Trophoblasts, invasion, and microRNA. Front Genet 2013;4:248.

22. Morales-Prieto DM, Chaiwangyen W, Ospina-Prieto $S$, et al. MicroRNA expression profiles of trophoblastic cells. Placenta 2012;33:725-734.

23. Chen AE, Egli D, Niakan $K$, et al. Optimal timing of inner cell mass isolation increases the efficiency of human embryonic stem cell derivation and allows generation of sibling cell lines. Cell Stem Cell 2009;4:103-106.

24. Benagiano G, Pala A, Meirinho $M$, et al. Biosynthesis of human chorionic gonadotrophin in vitro: incorporation of ( $14 \mathrm{C})$ L-leucine. J Endocrinol 1972;55:387-396.

25. Patrito LC, Flury A, Rosato J, et al. Biosynthesis in vitro of chorionic gonadotrophin from human placenta. Hoppe Seylers Z Physiol Chem 1973:354:1129-1132.

26. Tuckey RC. Progesterone synthesis by the human placenta. Placenta 2005:26:273-281.

27. Maldonado-Estrada J, Menu E, Roques $\mathrm{P}$, et al. Evaluation of Cytokeratin 7 as an accurate intracellular marker with which to assess the purity of human placental villous trophoblast cells by flow cytometry. J Immunol Methods 2004;286:21-34.

28. Moll R, Franke WW, Schiller DL, et al. The catalog of human cytokeratins: patterns of expression in normal epithelia, tumors and cultured cells. Cell 1982;31:11-24.

29. Vallier L, Alexander M, Pedersen RA. Activin/Nodal and FGF pathways cooperate to maintain pluripotency of human embryonic stem cells. J Cell Sci 2005;118(Pt 19):4495-4509.

30. Dalton S. Signaling networks in human pluripotent stem cells. Curr Opin Cell Biol 2013;25:241-246. 